\title{
Impaired coronary vasodilation with Regadenoson in patients with angiographically normal coronaries when compared to normal volunteers - Insights from Quantitative MRI Perfusion
}

\begin{abstract}
Sujethra Vasu*, W Patricia Bandettini, Li-Yueh Hsu, Peter Kellman, Marcus Y Chen, Joel Wilson, Steve Leung, Sujata M Shanbhag, O Julian Booker, Christine Mancini, Jennifer Henry, Tracy Lowrey, Andrew E Arai
\end{abstract}

From 2011 SCMR/Euro CMR Joint Scientific Sessions

Nice, France. 3-6 February 2011

\section{Introduction}

Quantitative myocardial perfusion to assess impaired coronary vasoreactivity has been used to identify subclinical atherosclerosis. Impaired coronary vasodilation has been observed in patients with cardiac risk factors in the MESA cohort. The coronary vasodilator response in patients with angiographically normal coronary arteries/ minimal stenosis is not known. The purpose of this study was to compare the stress myocardial blood flow (MBF) of patients with normal coronaries/minimal stenosis with normal volunteers.

\section{Hypothesis}

Patients with angiographically normal coronaries/minimal stenosis have impaired vasodilator response when compared to normal volunteers.

\section{Methods}

Twenty patients with normal coronaries/minimal stenosis on coronary $\mathrm{CT}$ angiography had also undergone stress MR with regadenoson. Seventeen healthy normal volunteers with Framingham score less than 1\% underwent stress testing with regadenoson. Using a SSFP

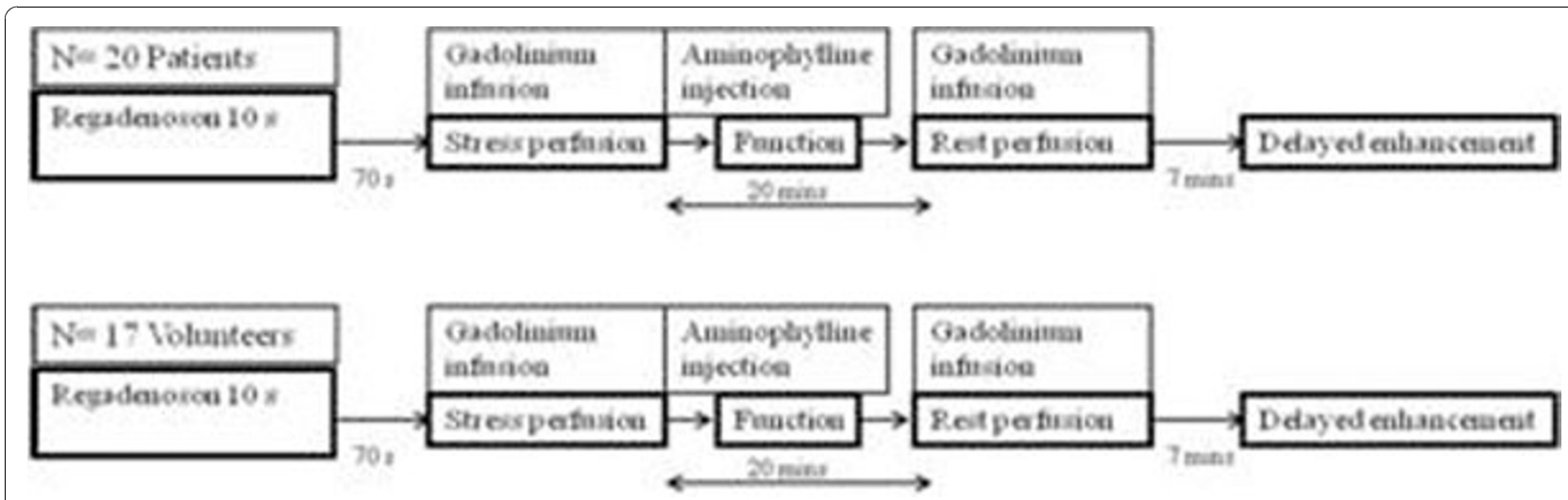

Figure 1 Study Design

National Institutes of Health, Bethesda, MD, USA

(c) 2011 Vasu et al; licensee BioMed Central Ltd. This is an open access article distributed under the terms of the Creative Commons 


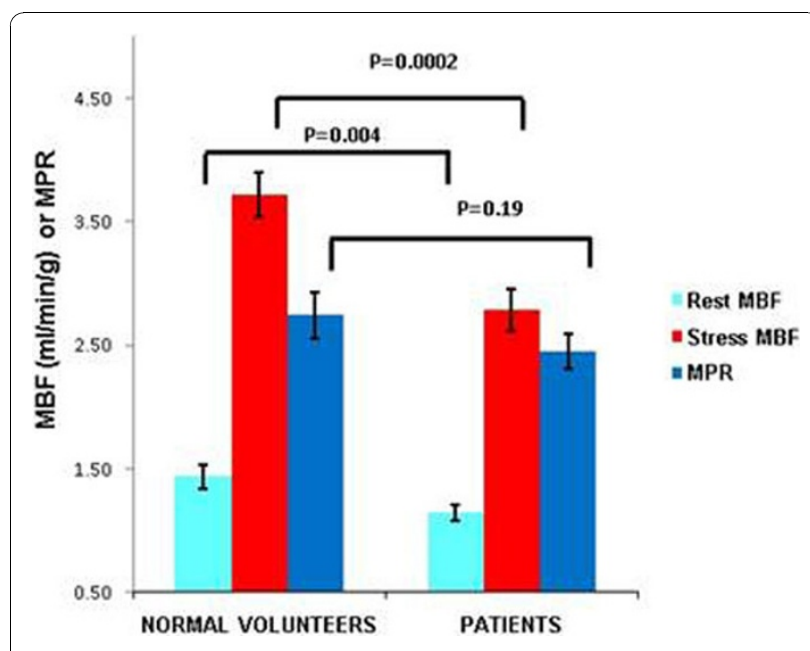

Figure 2 Rest, Stress MBF and MPR between normal volunteers and patients.

perfusion sequence, stress imaging was done 70 seconds post regadenoson injection. All patients and volunteers received aminophylline after stress imaging. Rest imaging was done 20 minutes later. Myocardial blood flow (MBF) in $\mathrm{ml} / \mathrm{min} / \mathrm{g}$ and myocardial perfusion reserve (MPR) were quantified using a fully quantitative model constrained deconvolution (MCD).

\section{Results}

Stress MBF (mean \pm standard error) was higher in normal volunteers $(3.72 \pm 0.18)$ than patients $(2.78 \pm 0.14)$, $\mathrm{p}=.0002$. When stratified by risk factors $(0-1,>1)$ the stress MBF of patients with $>1$ risk factor was significantly lower than young, healthy, normal volunteers ( $2.64 \pm 0.12$ vs. $3.72 \pm 0.18, \mathrm{p}=0.00005)$. Figures 1 and 2 .

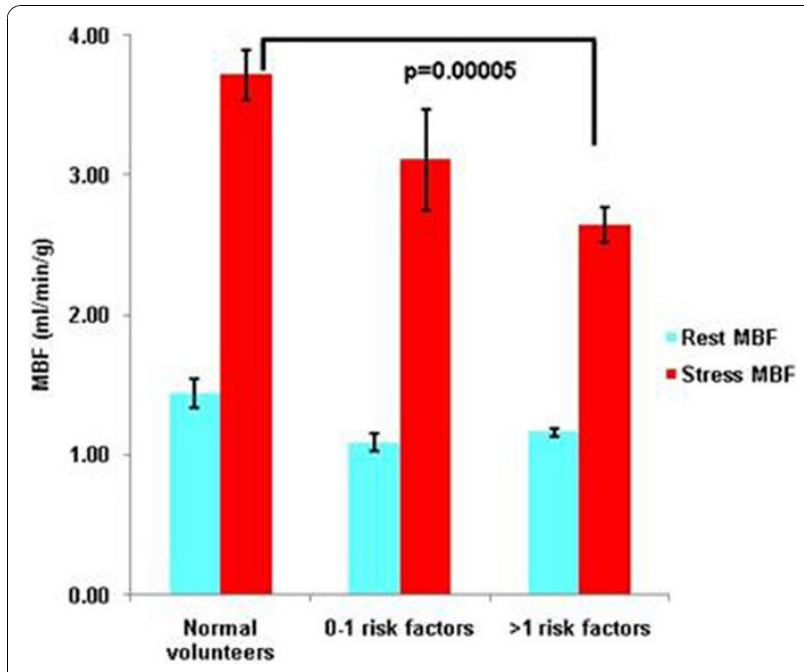

Figure 3 Rest and Stress MBF in normal volunteers and patients stratified by risk factors.

\section{Conclusions}

Despite angiographically normal coronaries/minimal stenosis on CT, patients referred for stress testing have impaired coronary vasodilator response relative to young, healthy normal volunteers. The magnitude of this effect is larger in patients with $>1$ risk factor.

Published: 2 February 2011

doi:10.1186/1532-429X-13-S1-066

Cite this article as: Vasu et al:: Impaired coronary vasodilation with Regadenoson in patients with angiographically normal coronaries when compared to normal volunteers - Insights from Quantitative MRI Perfusion. Journal of Cardiovascular Magnetic Resonance 2011 13(Suppl 1): O66.

Submit your next manuscript to BioMed Central and take full advantage of:

- Convenient online submission

- Thorough peer review

- No space constraints or color figure charges

- Immediate publication on acceptance

- Inclusion in PubMed, CAS, Scopus and Google Scholar

- Research which is freely available for redistribution 